\title{
The community health system in the DRC: An overview
}

Frontline Health Project

Follow this and additional works at: https://knowledgecommons.popcouncil.org/departments_sbsr-rh

Part of the Community-Based Research Commons, and the International Public Health Commons How does access to this work benefit you? Let us know!

\section{Recommended Citation}

Frontline Health Project. 2020. "The community health system in the DRC: An overview." Washington, DC: Population Council. 
The Community Health System in the DRC: An Overview

\section{HEALTH SYSTEM GOVERNANCE}

In the DRC, the community health system is decentralized and operates across five levels:

- At the national level, the Ministry of Health (MSP*) develops health policies and standards, and coordinates activities across donors and NGOs. The Community Participation Technical Working Group (GTTAP*) is a body comprised of different ministries, partners, civil society organizations, and private sector organizations that compiles, analyzes, and uses community-level data.

- At the provincial level, the provincial health division (DPS*) collects, analyzes, and interprets health data from the health zones in each of DRC's 26 provinces. There are 516 health zones in the country. At this level, the provincial development committee manages development issues in each province, and transmits provincial-level health data to the GTTAP.

- At the health zone level, the health zone management team plans and implements activities, collects and analyzes data from the health centers, and ensures service delivery.

- The health area is a subdivision of the health zone; each health area contains approximately one health center. The health area development committee (CODESA*) manages and mobilizes resources, oversees health service delivery, and ensures mechanisms for community participation.

- At the community level, the community outreach unit $\left(\mathrm{CAC}^{*}\right)$ is led by a village chief and other elected members of the community. The CAC holds monthly meetings, reports to the CODESA, and oversees community health workers known as relais communautaire (RECOs).

Figure 1 shows these key actors and their relationships.

\section{COMMUNITY HEALTH POLICY}

The community health system in DRC is guided by various policy documents. The National Health Development Plan (PNDS*) 2016-2020 is a framework to address health challenges such as inefficient human resources, and includes strengthening the roles of community members as a key pillar for health system improvement.

${ }^{*}$ Acronym is in French

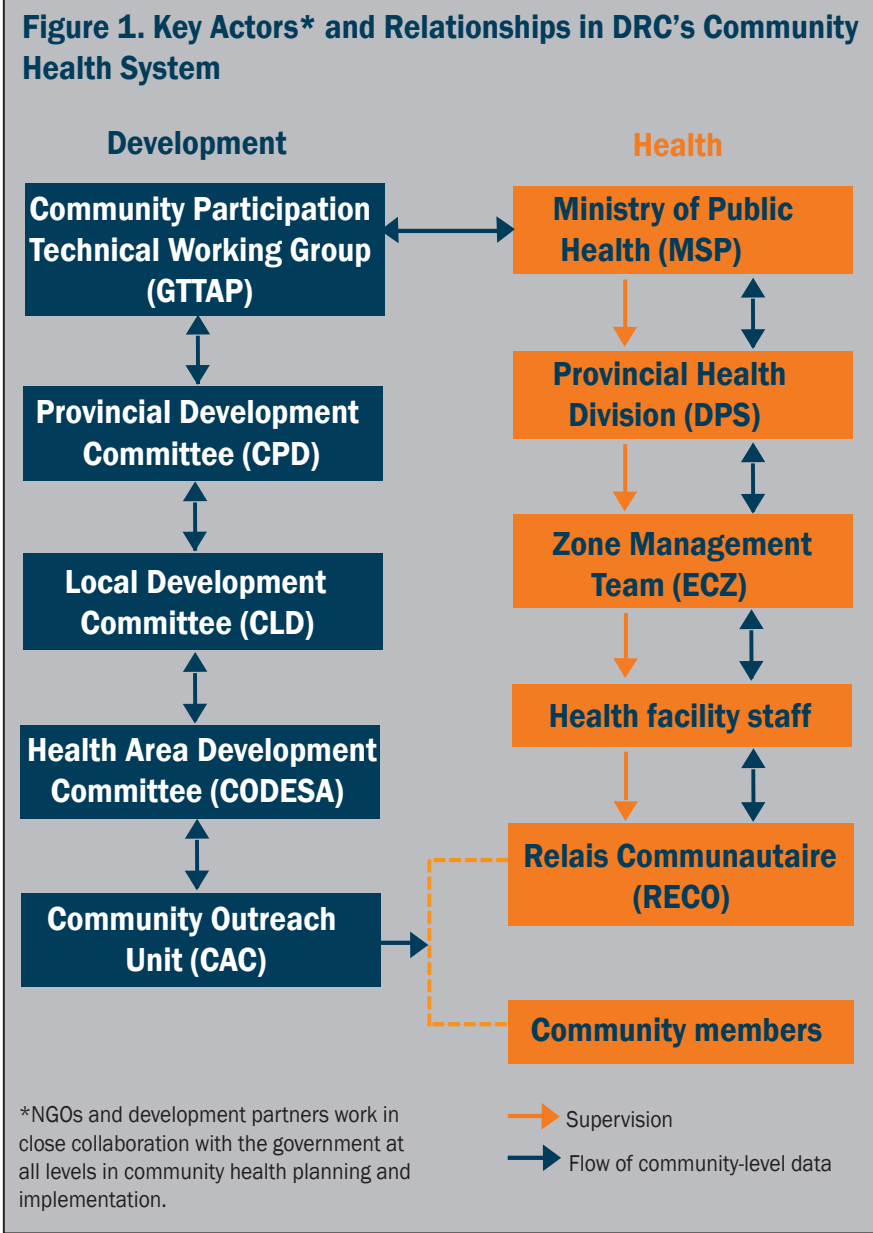

*Figure adapted from: Devlin K, Egan KF, Pandit-Rajani T. 2016. Community Health Systems Catalog Country Profile: Mali. Arlington, VA; Advancing Partners and Communities.

The main reference documents for community health, the Procedural Manual for Community Structures and Approaches and the Strategic Framework for Community Health Participation in the DRC, were developed in 2016. Together, these policies guide the monitoring and evaluation of community participation, known as PARTICOM*, and provide guidance for RECO activities.

\section{ROLE OF COMMUNITY HEALTH WORKERS}

Relais communautaire (RECOs) are the main cadre of community health workers operating in the DRC. They are volunteers who provide a minimum package of reproductive, maternal, newborn and child health (RM$\mathrm{NCH}$ ) services, including the provision of family planning; integrated community case management (iCCM) 
for malaria, diarrhea, and respiratory diseases; nutrition counseling; WASH, HIV and AIDS education; and disease prevention. RECOs provide services by conducting home visits to approximately 50 households per month. They also provide referrals to health facilities and conduct community-based surveillance. RECOs collaborate largely with the CAC to plan, implement, and monitor interventions and the services they provide.

After selection, RECOs undergo a basic training, with refresher and additional trainings for specific activities, such as vaccination campaigns. The CACs supervise RECOs and ensure that they complete monthly reports. Health facility staff and zone management teams may conduct supervision visits of RECOs.

Incentives that RECOs receive largely depend on the health zone in which they work. Incentives are also dependent on donor financing and are not provided by the government. While RECOs are considered largely volunteer and are not paid a salary, some are given a per diem for their work. In some districts, RECOs receive performance-based payments. Other non-financial incentives may include free or discounted health care; t-shirts; umbrellas; bicycles; formal social recognition; and opportunities for career advancement.

\section{REFERENCES}

1. Devlin K, Egan KF, Pandit-Rajani T. 2017. Community Health Systems Catalog Country Profile : Democratic Republic of Congo. Arlington, VA; Advancing Partners and Communities.

2. Ministère de la Santé Publique. 2016. Plan National de Developpment Sanitaire 2016-2020. Kinshasa, DRC: Government of DRC.

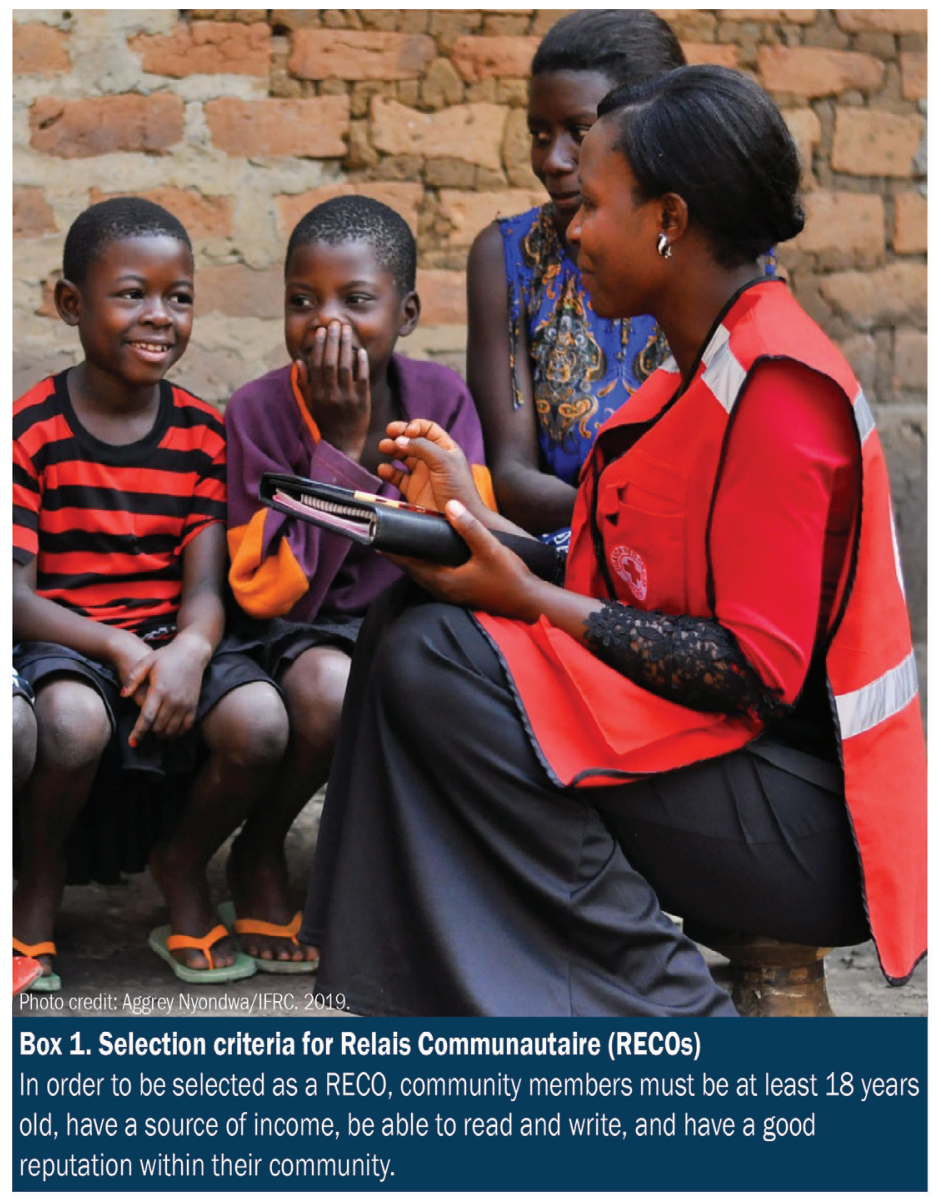

Suggested citation: Frontline Health Project. 2020. "The Community Health System in DRC: Overview." Washington, D.C.: Population Council. 